\title{
Belief in Counselling Effectiveness, Academic Self-concept as Correlates of Academic Help-Seeking Behavior among College Students
}

\author{
Shambel Molla Bizuneh \\ MEd in Educational Psychology, Department of Psychology, Education and Behavioral Sciences
}

\begin{abstract}
Effective counseling services enable students to the habit of requesting further help and develop a positive academic self-concept that further helps develop wellbeing and mental wholeness that results in academic excellence. Aim: understanding students' academic self-concept, academic help-seeking behaviors and beliefs towards belief in counseling effectiveness. It also describes the relationship between study variables. Methods: Based on a descriptive survey research design, a self-reported closed-ended questionnaire was administrated to 182 randomly selected college students at Sekota, Ethiopia. Analysis was made by using mean scores, standard deviation, independent sample t-test, Pearson correlation and multiple regression coefficients. Results: Independent-sample t-test revealed that male students' average scores were found to be significantly higher than female students' average scores in academic self-concept, help-seeking behavior and belief in counseling effectiveness. Correlation analysis confirmed that academic help-seeking behavior, belief in counseling effectiveness and academic self-concept is significantly correlated with one another. In this study, it was further found that $36 \%$ of the variance in academic help-seeking behavior can be accounted for by the variance of academic concept and belief in counseling service effectiveness. The overall regression was statistically significant, $\mathrm{F}(2,179)=51.28, \mathrm{R}^{2}=.36$. The independent contribution of predictor variables, the variance of belief in the effectiveness of counseling has significantly greater contributor as compared to academic selfconcept to the variance of academic help-seeking behavior. Conclusion: Hence, enhancement projects on academic self-concept and female students' belief in the effectiveness of counseling services should be taken as an agenda by teachers, college administrators, academic advisors and counselors.
\end{abstract}

Keywords: Academic Self-Concept; Help-seeking behavior; Belief; Counselling Effectiveness

DOI: $10.7176 / \mathrm{JEP} / 12-19-01$

Publication date:July $31^{\text {st }} 2021$

\section{Introduction}

Education is instrumental to change in the psycho-social and economic dimensions of nations, where growth is essential if the countries are to climb out of poverty. With this understanding, therefore, most nations, including Ethiopia today, have been investing much in accessing and providing quality education for their citizens than ever before (Bloom, Canning \& Chan, 2006; Wako, 2015; Ministry of education [MOE], 2018).

College student success is a critical issue for students, institutions of higher education, policymakers, parents, and other stakeholders (Fittrer, 2016). However, the transition from the protected environment at home and school to the independent life and learning environment in tertiary educational institutions have been stressful due to physical, mental, and emotional adjustments. It is a myth to assume that all tertiary educational institutions are the crime of the population and do not face any adjustment problems. Tertiary education for teenagers can be stressful as most of them live away from home and the learning system is entirely different from school (Greenidge, 2007; Njoka, 2014).

Through effective guidance and counseling services, fundamental assistance would enable them to develop a positive self-concept that further helps them experience psychological wellbeing and mental wholeness that results in academic excellence among college students (Corey 2005). A help-seeking model, designed for students, emphasizes the importance of deciding whom to ask for help. Scholars write, depending on who or what is targeted for help, learners' perceived benefits and expenses of seeking help from that source impact their likelihood of soliciting help (Makara \& Karabenick, 2013).

Counseling effectiveness is the satisfaction of the client by which the problem is solved relatively and persistently by the owner, and makes the client trust the provided service, however, counselors are generally poor at detecting a lack of client progress (Moloney, 2016), and typically overrating their effectiveness so that developing positive belief towards the counseling services becomes difficult. The effectiveness of counseling service is meaningful if it focuses on helping students to adjust themselves along with their school physical, social and academic environment (Kanga, 2017).

Gender is also an influential factor in the likelihood and willingness of college students to engage in adaptive help-seeking behaviors as a self-regulated learning strategy. There are differences in treatment based on gender and the internalization of gender-based stereotypes (Matthews, Marulis, \& Williford, 2014) throughout 
the lifespan in Western culture. Fear of embarrassment about asking for help develops in girls earlier than in boys (Newman, 2000). Female students usually like to request help support from their immediate person or families more than what males students do in their adolescence (Makara \& Karabenick, 2013). On the contrary, girls feel more warmth and assertion of capability from teachers than do boys (Newman, 2000). Girls, compared to boys, tend to ask for more help as tasks get increasingly more difficult (these bids for help do not equate to inadequate task completion) (Thompson, Cothran, \& McCall, 2012). Benenson and Koulnazarian (2008) reported that girls demand assistance more promptly than boys across both age and socio-economic levels.

Another factor that determines help-seeking behavior is academic self-concept. Research revealed that girls outshine boys on intellectual and behavioral self-regulation but not across standardized measures of academic achievement (Matthews et al., 2014). However, much more research on the relationship between gender and help-seeking exists for older children, adolescents, and adults. Because, as children grow older, gender socialization plays a greater role in how males and females think, feel, and act. For example, older girls begin to ask for the most help and consequently outperform older boys as well as younger boys and younger girls (Thompson, Cothran, \& McCall, 2012).

Looking ahead, it was of great interest to investigate the extent that Ethiopian gender norms affect college students' academic help-seeking behaviors. Since Ethiopian culture, most boys and men are dominant in expressing their interests. Females are shy to approach people around them including their elders in their respective homes. It is generally expected that women are not capable to perform and that they will not succeed at such academic posts. This stereotype of 'expected failure' implies that society doesn't trust in women's capacity to achieve. Affirmative actions also feed ideas that women are not able to achieve by themselves (Anouka et al., 2015). The belief about what men and women are capable of doing/not doing and how women and men are expected to behave can be influenced by traditional gender roles that are established in the human mind at an early age (Haile, Szendrö \& Szente, 2020). Ethiopia is one of the countries where gender equality is a vision but not yet a reality.

The relationships among academic help-seeking behavior, academic self-concept, and belief in the effectiveness of counseling have been studied several times. Investigating the relationship between belief in the effectiveness of counseling and help-seeking (Laxson, 2014; Al-Darmaki, 2011; Moloney, 2016) and between counseling and self-concept (Barongo \& Nyamwange, 2013; Otieno, 2016; Orlando \& Odera, 2014) were some of the recent studies. Studies indicated that students who have academic help-seeking behaviors and academic self-concepts are more beneficiaries than students who do not have academic help-seeking behaviors and academic self-concepts in their belief towards the effectiveness of counseling services (Schunk, 2000; Ng, 2014).

Regardless of such studies that are done in western countries, the results may not well address the nature of the issues in Ethiopia in which cultural influences have a great impact on variables under study. In my teaching experience, students are observed in problems while they are attending college education. Among fundamental problems which could be a problem among college students in many places or countries, academic cheating was the most serious problem. I have been checking students' assignments, invigilating them in tests and exams. In these cases, I found many students are copying assignments and cheating on exams. Therefore, this was triggering me to have the insight to assess students' academic self-concept, help-seeking behavior and their beliefs about academic counseling services. These problems more prevailed in female college students. College student success is a critical issue for students, institutions of higher education, policymakers, parents, and other stakeholders (Fittrer, 2016). However, the transition from the protected environment at home and school to the independent life and learning environment in tertiary educational institutions was stressful due to physical, mental and emotional adjustments. It is a myth to assume that all tertiary educational institutions are the crime of the population and do not face any adjustment problems. Tertiary education for teenagers can be stressful as most of them live away from home and the learning system is entirely different from school (Greenidge, 2007; Njoka, 2014).

Previous research on help-seeking behavior has also helped establish the importance of gender when considering possible sex differences in help-seeking behavior. Johnson (1988, cited Marrs, Sigler \& Brammer, 2012) examined the role of sex and gender attributes on help-seeking attitudes or attitudes towards counseling among college undergraduates and found that both gender and sex roles were important for understanding attitudes. Researchers have also found that gender is a significant factor in the acquisition of self-identification. Gender-typical behavior is brought about by individuals having their sense of self through the lens of gender (Baron, Schmader, Cvencek \& Meltzoff, 2014). According to Goldman and Penner (2016), when examining gender differences in self-concept, country-level factors are present and influential. A study done among 49 countries on all the continents, found that gender-egalitarian countries have minimal gender differences in selfconcept, specifically academic self-concept (Goldman \& Penner, 2016). Thus, this implied that cultural perspectives on self-concept, career choice, and gender are influenced by country-level factors.

Some studies found no statistically significant relationship between gender and academic self-concept. Females who are in technical fields have had to go against negative cultural stereotypes through collaborative 
learning to succeed in male-oriented careers (Stout \& Tamer, 2016). However, there exist disparities in findings among previous research and the degree of importance of the issues for college students' success. And these triggered the researcher of this study to coin and examine the relationship between academic help-seeking behavior, academic self-concept, and beliefs in counseling services effectiveness.

To sum up, this study was planned to describe the comparative status of college students' belief in the effectiveness of counseling, academic self-concept, and help-seeking behavior in gender. This study also scrutinized the relationship between study variables and identified which variable is important to predict students' academic help-seeking behavior at Sekota College of Teachers Education, Ethiopia.

In an attempt to address the objective of the study, the following research questions are outlined:

- Are there significant differences between male and female students in academic self-concept, helpseeking behavior, and beliefs in counseling effectiveness?

- Are there significant relationships between academic self-concept, help-seeking behavior, and the effectiveness of counseling services?

- To what extent do students' academic self-concept and belief in counseling effectiveness influence their academic help-seeking behavior?

\section{Methods}

\section{Design and population of the study}

The design of this study was correlational and followed both quantitative and qualitative research. The study was conducted on Sekota College of Teacher Education students. The initial sampling frame was defined as all college students in Sekota CTE. Students in Sekota CTE were 1020 in number. Students were selected using a stratified sampling technique. Accordingly, first, all levels of the program (first, second and third year), departments, and sections were considered comprehensively, but the number of students from each section was selected using proportionate stratified sampling where the strata were departments, level of the program, and sections. Finally, individual students were selected by systematic sampling technique as a complete list of students was taken from the registrar's office.

Yamane (1967:886) provides a simplified formula to calculate sample sizes and calculate the proportion from each stratum. This formula was used to calculate the sample sizes and is shown below. A $95 \%$ confidence level and $P=.05$ are assumed for this Equation Where $\mathrm{n}$ is the sample size, $\mathrm{N}$ is the population size, and e is the level of precision. When this formula is applied to the above sample,

$$
\begin{aligned}
& \mathrm{n}=820 \div 1+820(0.05)^{2} \\
& \mathrm{n}=269
\end{aligned}
$$

Then, to get the sample size from each department and year, the proportional index was calculated by dividing the sample size to the total population (proportional index=Total sample size/Total population $=269 / 820=.33)$. Following this, the sample size from each department from two groups $\left(1^{\text {st }}\right.$ and $2^{\text {nd }}$ year $)$ was determined by multiplying the population of each stratum by 0.33 .

\section{Instrumentation}

To perform data collection, a closed-ended self-completed questionnaire was used. In addition, an interview was carried out. The questionnaire was used to get data on academic self-concept, help-seeking behavior, and belief in counseling service effectiveness.

Students' academic self-concept items were developed from Bei, Tan, \& Yates (2007). The Academic SelfConcept Questionnaire (ASCQ) was adapted by restating (2), adopting (13), and inserting (1) words or ideas or items. The questionnaire was rated on a 5-point Likert scale as of $5=$ Strongly Agree (SA); 4=Agree (A); 3=Undecided (UD); 2=Disagree (DA); and 1=Strongly Disagree (SDA).

Help-Seeking Behavior items were designed by Elhai, Schweinle, \& Anderson (2008). Help-seeking behavior is measured by the attitudes toward seeking professional psychological help scale. In previous, reliability of items of this academic help-seeking behavior was ranging from(r=.77) to (r=.84) (Elhai, Schweinle, $\&$ Anderson, 2008). This scale assesses an individual's attitudes toward seeking help from professionals. It was used by adopting (8), restating (11), omitting (6), and inserting (7) words or ideas or items of the questionnaire to be matched with the objective of the study (26 items were set for final utilization of this research). Items were rated on a 5-point Likert scale that ranges from "strongly disagree" (1) to "strongly agree" (5).

The belief in counseling effectiveness scale was used to gather data from students' beliefs towards the effectiveness of counseling services. The questionnaire was developed by Musika \& Bukaliya (2015). It was developed by restating (13), omitting (5), adopting (7), and inserting (5) words or ideas or items of the questionnaire to be matched with the objective of the study (25 items were set for final utilization of this research). Items are rated on a 5-point Likert scale that ranges from "strongly disagree" (1) to "strongly agree" (5).

A Semi-structured interview was used to gather data from students about all variables (academic help- 
seeking behavior, academic self-concept, and belief in the effectiveness of counseling service) to validate the results obtained from the closed-ended questionnaire.

\section{Procedures of Data Collection}

A pilot study was carried out to confirm the reliability and validity of the questionnaires by translating them into the language to minimize ambiguities on the part of the respondents. The questionnaire was administered to sixty-two (62) respondents who were selected for the pilot study by a simple random sampling technique from Sekota College of Teacher Education. During the pilot test, the participants were informed to put question marks in front of each item that was not clear to them. All administered questionnaire papers were collected. After collecting the questionnaire papers, each item was checked to see whether students responded to it appropriately. After the pilot study, items that were confusing and had clarity problems were rephrased, modified to fit the purpose of the study. Accordingly, 3 items of academic help-seeking behavior (out of 29 items), 5 items of effective counseling (out of 30 items), and 4 items of academic self-concept (among 20 items) were deleted. The total drafted items for the main study were 66. On average, computation of split half-reliability coefficient resulted $(\mathrm{r}=.82)$ for final data collection.

To check items validity, the questionnaires were given to three psychology educators to put their comments regarding items' deservingness with the title. A modified questionnaire was administered to respondents.

After clear orientation was given for three data collections, the questionnaire was administered to participants during class time. Permission was asked from respective classroom teachers who were found delivering class sessions. Completion of the questionnaire was done in the presence of the administrators. In addition to the questionnaire, using a simple random sampling technique, ten students (five per year level students) were recruited for an interview out of 204 randomly selected respondent samples. The interview was carried out in an environment where the interviewer and interviewees agreed when respondents could be relatively free.

\section{Data Analysis}

Analysis was made after the data was structured and sorted in SPSS version22; mean, standard deviations, Pearson Correlation coefficient, multiple regression coefficients, and independent t-test analyses were conducted. Inter-correlation analyses were applied to judge and see the relationship between academic self-concept, helpseeking behavior, and belief in counseling effectiveness. Multiple regression analysis was implemented to see the contribution of independent variables (academic self-concept and belief in counseling effectiveness) to variation of the dependent variable (academic help-seeking behavior). An independent t-test was used to assess gender differences in academic self-concept, help-seeking behavior, and belief in counseling effectiveness.

\section{Compliance with Ethical Standards}

Before administration of the questionnaire, informed consent was made among respondents; clear orientation was given about the purpose of the questionnaire, how to score it, and how much time it lapses. To ensure the safe running of the study, a permission letter was obtained from the college office as well as consensus was reached by college deans. All information collected from participants of the study was cleared for all concerned bodies as it was confidential.

\section{Results}

It was proposed to see differences in the status of male and female students in study variables. In response to this objective mean, standard deviation, and independent-sample t-test were computed and the result was present in table1.

Table1

Gender Difference in Study Variables

\begin{tabular}{lccccc}
\hline \multicolumn{1}{c}{ Variable } & Gender & Mean & SD. & t-value & Df \\
\hline Academic Help-Seeking Behavior & Male & 3.81 & 0.38 & $4.48^{* *}$ & 180 \\
& Female & 3.51 & 0.51 & & \\
Belief in Counseling effectiveness & Male & 4.44 & 0.30 & $7.47^{* *}$ & 180 \\
& Female & 3.98 & 0.50 & & \\
Academic Self-Concept & Male & 4.83 & 0.29 & $4.69^{* *}$ & 180 \\
& Female & 4.47 & 0.43 & & \\
\hline
\end{tabular}

**. The mean score difference is significant at 0.01 ( 2-tailed).

Table1 indicated that in help-seeking behavior, male students' mean scores $(\mathrm{M}=3.81, \mathrm{SD}=0.38)$ were found to be significantly higher than female students $(\mathrm{M}=3.51, \mathrm{SD}=0.51)$, where $\mathrm{df}=180), \mathrm{t}=4.48$ at $\mathrm{P}<0.01$. The results presented in the above table1 revealed the t-value of the mean scores of academic self-concept with reference to gender. An independent-samples t-test was conducted to compare the mean scores of academic self- 
concept between male and female subjects. The results showed that there is a significant difference in the mean scores of academic self-concept between male and female subjects. Males have higher levels of academic selfconcept $(\mathrm{N}=91, \mathrm{M}=4.83$., $\mathrm{SD}=0.29)$ than females $(\mathrm{N}=91, \mathrm{M}=4.47, \mathrm{SD}=0.43)$; $\mathrm{t}=4.69$, $\mathrm{df}=180$, at $\mathrm{p}<.01$.

Furthermore, in table1 an independent-samples t-test was conducted to compare the mean scores of belief in counseling service effectiveness between male and female subjects. The results showed that there is a significant difference in the mean scores of belief in counseling service effectiveness between male and female subjects. Males have higher levels of academic self-concept $(\mathrm{N}=91, \mathrm{M}=4.44$., $\mathrm{SD}=0.30)$ than females $(\mathrm{N}=91, \mathrm{M}=3.98$, $\mathrm{SD}=0.50) ; \mathrm{t}=7.47, \mathrm{df}=180$, at $\mathrm{p}<0.01$.

The second objective of this study was to investigate the relationship between study variables. Given the current data, the correlation of academic self-concept, belief in the effectiveness of counseling service, and academic help-seeking behavior was seen. The analysis result of each correlation is presented below.

Table 2

Relationship between Study Variables

\begin{tabular}{|c|c|c|c|c|}
\hline No. & Variable & 1 & 2 & 3 \\
\hline 1 & Academic Help-Seeking Behavior & - & & \\
\hline 2 & Belief in Counseling Service effectiveness & $.591^{* *}$ & - & \\
\hline 3 & Academic Self-Concept & $.455^{* *}$ & $.608^{* *}$ & - \\
\hline
\end{tabular}

**. Correlation is significant at the 0.01 level (2-tailed).

Table (2) shows that academic self-concept, academic help-seeking behavior, and belief in the effectiveness of counseling service of college students are positively and significantly correlated to each other. However, the magnitude of the relationship is different from one another. Academic help-seeking behavior is significantly correlated with belief in the effectiveness of counseling service at degree correlation coefficient $(\mathrm{r}=.59)$ at $\mathrm{P}<$ 0.01. Belief in the effectiveness of counseling service is significantly correlated with academic self-Concept at the degree of Pearson's correlation coefficient $(\mathrm{r}=.61)$ at $\mathrm{P}<0.01$. It shows that students with high academic concepts have high beliefs about the effectiveness of counseling services tend to manifest help-seeking behavior. Last, Academic Self-Concept is significantly correlated with Academic help-seeking behavior at the degree of Pearson's correlation coefficient $(\mathrm{r}=.46)$, at $\mathrm{P}<0.01$.

In response to the third objective was to investigate the magnitude of the contribution of predictive variables to the criterion variable. The analysis result of multiple linear regressions is presented below.

Table3a

Model Summary: Effect of Predictor Variables on the Criterion Variable

$\begin{array}{lllll}\text { Model } & \mathrm{R} & \mathrm{R} \text { square } & \text { Adjusted R square } & \begin{array}{l}\text { Std. Error of the } \\ \text { Estimate } \\ 1\end{array} \\ .603^{\mathrm{a}} & .364 & .357 & .38065\end{array}$

When we square $\mathrm{R}=.60$, we obtained $\left(\mathrm{R}^{2}=.36\right) . \quad R^{2}$ represents the correlation between all the exploratory variables together with the criterion variable. This means all the variance (both shared and unique) of the exploratory variables in relation to the criterion variable. In our particular sample, $36 \%$ of the variance in academic help-seeking behavior can be accounted for by high academic concepts and belief in counseling service effectiveness. However, SPSS adjusts this figure downwards to give an estimate of the population $R^{2}$. This is because the sample regression line fits the sample better than it does the population (since it is the bestfitting line for the sample). Thus, we can say we have accounted for $36 \%$ of the variance in criterion variables by our explanatory variables.

Table3b

Model Summary: Status of Predictor Variables on the Criterion Variable as Tested by F

\begin{tabular}{|c|c|c|c|c|}
\hline \multirow[t]{2}{*}{ Model } & \multicolumn{2}{|c|}{$\begin{array}{l}\text { Unstandardized } \\
\text { Coefficients }\end{array}$} & \multirow{2}{*}{$\begin{array}{c}\text { Standardized } \\
\text { Coefficients } \\
\text { Beta }\end{array}$} & \multirow[t]{2}{*}{ T-value } \\
\hline & $\mathrm{B}$ & Std. Error & & \\
\hline (Constant) & 0.695 & 0.341 & \multirow[b]{2}{*}{0.499} & $2.039 * *$ \\
\hline $\begin{array}{l}\text { Belief in Effectiveness of Counseling } \\
\text { Service }\end{array}$ & 0.501 & 0.075 & & $6.643 *$ \\
\hline Academic Self-Concept & 0.185 & 0.092 & 0.152 & $2.022 *$ \\
\hline
\end{tabular}

Note: The independent variable is Academic Hel Seeking Behavior.

**. Beta coefficient is significant at the 0.01 level (2-tailed).

Table (3a) showed that the explanatory variables together predict the criterion variable. The ANOVA shows us that the regression plane for these variables departs significantly from 0 - in other words, we can predict Help-Seeking Behavior that can be accounted for from academic self-concept, belief in the effectiveness of counseling service together. The overall regression was statistically significant, $F(2,179)=51.28, R^{2}=.36$. In table $3 \mathrm{~b}$ we can see the degree of importance of the explanatory variables by looking at the standardized weights $($ beta $=)$ and the level of significance. From the given explanatory variables, belief in the effectiveness of 
counseling service $(=-.49, \mathrm{t}=6.64$ at $\mathrm{P} 0.05)$ and academic Self-Concept $(=.15, \mathrm{t}=2.022$ at $\mathrm{P} 0.05)$ are independently significant predictors of academic help-seeking behavior.

\subsection{Discussion}

\section{Status of Males and Female students in Study Variables}

In response to the first objective of this study, it is revealed that the average mean score of male students in helpseeking behavior was found to be significantly higher than female students. This indicates when students face academic difficulties like classroom learning, project work, assignments, or books they are referring to male students who are more seeking solutions from their peers, teachers, or anyone they believe a solution can be available. However, this result in help-seeking behavior is in this study was found different from other previous results. Atkinson, Lowe, and Matthews (1995) did not find gender differences in willingness to seek academic help from either people around them for personal or academic concerns. In addition, Masuda and Suzumura (2005) reported that Japanese males and females did not differ significantly in their help-seeking behavior.

The study also revealed that males have higher levels of academic self-concept than females. This means male students are on average better than female students in their understanding of academic competence, including completing projects, assignments and solving classroom exercises; responding to teachers' questions, understanding learning materials, and referring to books and or similar sources. This research result is also similar to other research results. For instance, research by Stoufe and Coupper (2016), and Albert \& Dahling (2016)) revealed that, comparatively, boys have a more powerful academic self-concept than girls. They think confidently, realistically, and effectively. However, a study conducted by Nabi, Karimi, Muthuri \& Arasa (2017) on the total sample indicated that the coefficients for the academic self-concept variables were not statistically significant in gender variables. This means female scores in academic self-concept are comparably similar to male scores.

The findings of this study in academic self-concept and help-seeking behavior indicated that the higher the self-concept is associated with higher value in help-seeking behavior. This is opposite to the theoretical explanation that feelings of inadequacy are also often amplified by individuals' natural tendency to engage in social comparison, which in instances requiring assistance, is often accompanied by feelings of inferiority, low self-esteem, and embarrassment. Research in Kenya has also documented that self-concept is related to academic achievement (Mwaniki, 2003, Ondeche, 2005 and Otelo, 2005; cited in Otieno \& Odera, 2014). Academic selfconcepts determine learners' academic performance and raise their internal locus of control. It's also a way of anchorage of life skills in ones' personality so that males develop a higher level of competence than female ones (Otieno and Odera, 2014).

\section{Belief in Counseling Effectiveness, Academic Self-Concept, and Academic Help-Seeking Behavior}

In response to the second objective, the result of this study revealed that all study variables are correlated with each other. Academic help-seeking behavior is significantly correlated with belief in the effectiveness of counseling services. Belief in the effectiveness of counseling service is significantly correlated with academic self-Concept. Last, Academic Self-Concept is significantly correlated with Academic help-seeking behavior.

The study showed that students, with high academic concepts, have high beliefs about the effectiveness of counseling, tend to manifest help-seeking behavior. This means the increment or decrement of the value of one variable is directly related to the increment or decrement of the value of another variable. In specific terms, when increment of value of academic self-concept is directly related to increment of either help-seeking behavior, there would also increment of beliefs in the effectiveness of counseling services or vice versa. This research result is similar to the notion of educational discipline. For example, educational psychology research has identified many aspects of successful retention of students inside the educational system, focusing, among others, on building students' cognitive and motivational skills (Wiseman and Messitt, 2010; Drake, 2011) to improve students' academic success.

It has been indicated in the result section that belief in the effectiveness of counseling service and academic self-concept significantly correlate with academic help-seeking behavior. This doesn't show how high the effects of these predictor variables contribute to the variance in academic help-seeking behavior. Hence, the multiple linear regression analysis revealed that we have accounted for $36 \%$ of the variance in criterion variables by our explanatory variables. And the higher contribution is counted by belief in the effectiveness of counseling service $(=-.49)$ as compared to academic self-concept $(=.15)$.

\section{Conclusion and Implications}

From this study, it can be concluded that academic self-concept and belief in the effectiveness of counseling service influence college students to understand their goals by then they develop academic help-seeking behavior which plays an effective role in making decisions about the importance of help-seeking. When a person moves towards a goal, he/she needs a helping hand to guide him/her appropriately. To understand the academic 
behavior of students and lead them to academic excellence, educators, counselors, department-level advisors, and education leaders should begin by understanding what motivates students to engage in help-seeking behaviors, developing positive belief in the effectiveness of counseling service and designing strategies to enhance student's academic self-concept. The finding of this study also indicated that females have a lower academic self-concept than males so that these findings have many implications for providing help and effective advising to students, especially for those female students who are in the initial years of their academic studies who may be experiencing academic difficulties This enhances their belief in para counseling service effectiveness so that they will develop high academic help-seeking behavior.

\section{References}

Albert, M. \& Dahling, J. (2016). Learning goal orientation and locus of control interact to predict academic selfconcept and academic performance in college students. Journal of Personality Psychology, 97, 245-248. DOI: 10.1016/j.paid.2016.03.074

Al-darmaki, F. R. (2011). Needs and attitudes toward seeking professional help and preferred sources of help among Emirati college students. Journal for International Counselor Education, 3, 39-57.

Anouka, E., Franz, W., Fetenu, B., Lenesil, A., \& Mahlet, M. (2015). Female faculty and leadership: Affirmative action and gender equality in 13 universities in Ethiopia. 1(1), 1- 16.

Baron, A. S., Schmader, T., Cvencek, D., \& Meltzoff, A. N. (2014). The gendered self-concept: How implicit gender stereotypes and attitudes shape self-definition. In P. J. Leman \& H. R. Tenenbaum (Eds.), Current issues in developmental psychology. Journal of Gender and development, 109-113.

Barongo, S., \& Nyamwange, C. (2013). Contribution of self-concept in guidance and counseling among students. Research on Humanities and Social Sciences, 3 (13), 7-13.

Bei, J., Tan, Y., \& Yates, S. M. (2007). A Rasch analysis of the Academic Self-Concept Questionnaire. International Education Journal, 8 (2), 470-484.

Bitz, K. (2010). Measuring advisor relationship perceptions among first-year students at a small Midwestern university. NACADA Journal. 30 (2): p. 53-64.

Bloom, D.E., Canning, K. \& Chan, D. (2006). Higher education and economic growth in Africa. International Journal of African Higher Education, 1 (1), 24-57.

Bransford et al. (2000). How People Learn: Brain, Mind, Experience, and School (and J. W. P. M. Suzanne Donovan, John D. Bransford \& Editors, Eds.). Washington, D.C

Corey, C. (2005). Theory and Practice of Counseling \& Psychotherapy. ( $7^{\text {th }}$ ed.). Belmont, CA: Thomson Learning.

Drake, J.K. (2011). The role of academic advising in student retention and persistence. About Campus, 16 (3), 812. https://doi.org/10.1002/abc.20062

Elhai, J. D., Schweinle, W., Anderson, S. M. (2008). Reliability and validity of the attitudes toward seeking professional psychological help scale-short form. DOI: 10.1016/j.psychres.2007.04.020

Fittrer, P. (2016). Academic help-seeking constructs and group differences: an examination of first-year university students. Unpublished Dissertation. University of Nevada: Reno.

Goldman, D.A. \& Penner, M.A. (2016). Exploring international gender differences in Mathematics self-concept. International Journal of Adolescent and Youth, 21 (4), 403-418. Doi: 10.1080/02673843.2013.847850

Greenidge, W. (2007). Attitudes towards seeking professional counseling: the role of outcome expectations and emotional openness in English-speaking. Unpublished Thesis, 1-71.

Haile, V., Szendrö, K., Szente,V. (2020). Recent issues in sociological research. Economics \& Sociology, 13(2), $136-150$

Kanga, B. M. (2017). Effectiveness of Guidance and Counselling Services in Enhancing Students' Adjustment to the School Academic Environment in Public Boarding Secondary Schools in Kenya. International Journal of Innovation and Education Research, 5 (7).

Laxson, K. D. (2014). Who Asks For Help? : Help-Seeking Attitudes Among Liberal Arts Students.

Makara, K. A., \& Karabenick, S. A. (2013). Characterizing sources of academic help in the age of expanding educational technology: A new conceptual framework. In S. A. Karabenick \& M. Puustinen (Eds.), Advances in help-seeking research and applications: The role of emerging technologies. Charlotte, NC: Information Age Publishing

Marrs, H., Sigler, E. A. \& Brammer, D. R. (2012). Gender, Masculinity, Femininity, and Help-Seeking in College. Masculinities \& Social Change, DOI: 10.17583/msc.2012.392

Matthews, S.J., Marulis, M.L. \& Williford, P.A. (2014). Gender processes in school functioning and the mediating role of cognitive self-regulation. Journal of Applied Developmental Psychology 35 (3):128-137. DOI: $10.1016 /$ j.appdev.2014.02.003

Federal Democratic Republic of Ethiopia Ministry of Education (2018). Annual educational report. Addis Ababa. Masuda A, and Suzumura K. (2005). United States and Japanese college students' attitudes toward seeking 
professional psychological help. Int J Psychol. vol40:303-313.

Moloney, L. (2016). Defining and delivering effective counseling and psychotherapy. Family Information Exchange, CFCA PAPER NO. (38).

Musika, F., \& Bukaliya, R. (2015). The Effectiveness of Counseling on Students 'Learning Motivation in Open and Distance Education. 2 (7), 85-99.

Nabi, R., Karimi D., Muthuri andArasa J. N. (2017). Gender Differences in Self-Concept among a Sample of Students of the United States International University in Africa. Nairobi, Kenya.

Newman, R. S. (2000). Social Influences on the Development of Children's Adaptive Help Seeking: The Role of Parents, Teachers, and Peers. Developmental Review, 20(3), $350-404$

Ng, M. (2014). Self-efficacy beliefs and academic help-seeking behavior of Chinese students. Journal of Educational Sciences and Psychology, 5 (1), 17-31.

Njoka, J. N. (2014). Guidance and Counseling: Theories and Approaches to Effective Students' Support in Technical Education in Kenya. 7 (2074), 1-10.

Olando, K. \& Odera, P. (2014). Effectiveness of Guidance and Counseling Services on Adolescent Self-concept in Khwisero District, Kakamega County. International Journal of Human Resource Studies, 4(4), 1-9. https://doi.org/10.5296/ijhrs.v4i4.6498

Otieno, K. (2016). Effectiveness of Guidance and Counseling Services on Adolescent Self-concept in Khwisero District, Kakamega County. https://doi.org/10.5296/ijhrs.v4i4.6498

Onyango, P.A., Jairo, P. Aloka, P. R. (2018). Effectiveness of Guidance and Counseling in the Management of Student Behaviour in Public Secondary Schools in Kenya.

Payakachat, N., Gubbins, P. O., Ragland, D., \& Norman, S. E. (2018). Academic Help Seeking Behavior Among Student Pharmacists. 77 (1), 1-12. https://doi.org/10.5688/ajpe7717

Schunk, D., \& Ertmer, P. (2000). Self-regulation and academic learning: Self-efficacy enhancing interventions. In M. Boekaerts, P. Pintrich, \& M. Zeidner (Eds.), Handbook of self-regulation (pp. 631-649). San Diego: Academic Press.

Schunk, D. H. (2005). Self-Regulated Learning: The Educational Legacy of Self-Regulated Learning: The Educational Legacy of Paul R. Educational Psychologist, $40 \quad$ (2) 85-94. https://doi.org/10.1207/s15326985ep4002

Schunk, D. H. (2012). Learning Theories: An Educational Perspective (6 ${ }^{\text {th }}$ Ed.). Boylston Street, Boston.

Stout, G. \& Tamer, B. (2016). The grade cohort workshop: evaluating an intervention to retain women, graduate students. Journal of Frontier Psychology,7,1-16.

Thompson, B.R. Cothran, T. \& McCall, D. (2012). Gender and age effects interact in preschoolers' help-seeking: Evidence for differential responses to changes in task difficulty. Journal of Child Language, 39 (5), 1107 1120

Wiseman, C. and H. Messitt (2010). Identifying components of a successful faculty-advisor program. NACADA Journal. 30 (2), 35-52. 